\title{
Review Article \\ Status and Challenges on Design and Implementation of Camber Morphing Mechanisms
}

\author{
Tuba Majid $\mathbb{D}^{1}$ and Bruce W. Jo $\mathbb{D}^{1,2}$ \\ ${ }^{1}$ Department of Mechanical Engineering, State University of New York (SUNY) Korea, Stony Brook University, \\ Incheon 21985, Republic of Korea \\ ${ }^{2}$ Department of Mechanical Engineering, Stony Brook University, Stony Brook 11794, USA
}

Correspondence should be addressed to Bruce W. Jo; bruce.jo@stonybrook.edu

Received 3 August 2021; Revised 27 October 2021; Accepted 20 November 2021; Published 14 December 2021

Academic Editor: Enrico Cestino

Copyright (c) 2021 Tuba Majid and Bruce W. Jo. This is an open access article distributed under the Creative Commons Attribution License, which permits unrestricted use, distribution, and reproduction in any medium, provided the original work is properly cited.

\begin{abstract}
This paper presents state-of-the-art technologies of camber morphing mechanisms from the perspectives of design and implementation. Wing morphing technologies are aimed at making the aircraft more energy or aerodynamically efficient during flight by actively adjusting the wing shape, but their mechanism designs and implementation aspects are often overlooked from practical sense in many technical articles. Thus, it is of our interest that we thoroughly investigate morphing mechanisms and their nature of design principles and methodologies from the implementation and test flight aspects, navigate the trends, and evaluate progress for researchers' methodology selection that possibly turns to design and build stages. This paper categorizes the camber morphing mechanisms from a wide collection of literature on morphing wings and their mechanisms, and the defined classifications are based on mechanism's design features and synthesis methodology, i.e., by the tools and methods used to solve the design problem. The categories are (1) structure-based, (2) material-based, and (3) hybrid. Most of the structure-based camber morphing mechanisms have distinctive structural features; however, the material-based camber morphing mechanisms make use of material properties and tools to enhance the elastic nature of its structures. Lastly, the hybrid morphing mechanisms are a combination of both the aforementioned categories. In summary, this review provides researchers in the field of morphing mechanisms and wings with choices of materials, actuators, internal and external structure design for wings, and overarching process and design methodologies for implementation with futuristic and practical aspects of flight performance and applications. Moreover, through this critical review of morphing mechanism, selective design criteria for appropriate morphing mechanisms are discussed.
\end{abstract}

\section{Introduction}

The term "morphing" is a discipline of Smart Structures [1] and is associated with giving systems additional capabilities to adapt to external changes. Wing morphing refers to changing the shape of aircraft wings during flight, in a smooth and continuous manner. Whereas a conventional wing aircraft has a selected airfoil that could only be optimal for one flight condition, morphing wings are designed to optimize the geometry of its wings to correspond to desired flight conditions. A comparison between the conventional shape-changing devices used on a conventional wing aircraft versus the morphing mechanisms of a morphing wing air- craft is presented visually in Figure 1 and explained in Table 1 to highlight the potential benefits of morphing.

Wing morphing can be classified into three broad categories: in-plane morphing, airfoil morphing, and out-ofplane morphing [9] as shown in Figure 2. In-plane morphing covers any changes of wing configuration in the $x$ and $y$ plane: span, chord, and sweep; airfoil morphing describes changes in the airfoil shape: change in the camber rate and camber thickness; out-of-plane morphing covers changes in the $z$ plane (vertical direction): the spanwise bending and twist. Amongst them, this paper focuses on fine-scale airfoil morphing: camber change, referred to as camber morphing, i.e., change in camber rate, hereafter referred to 


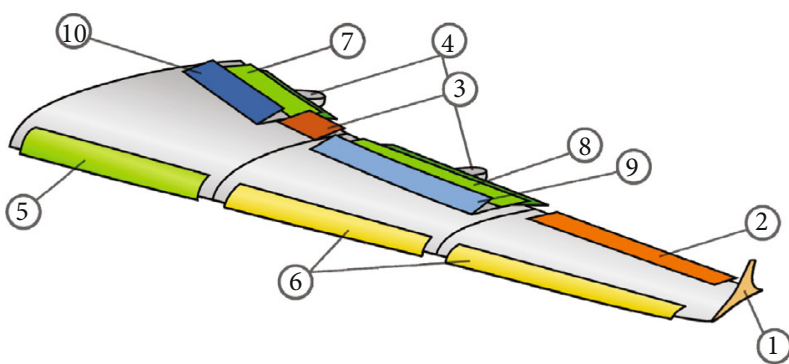

(a)

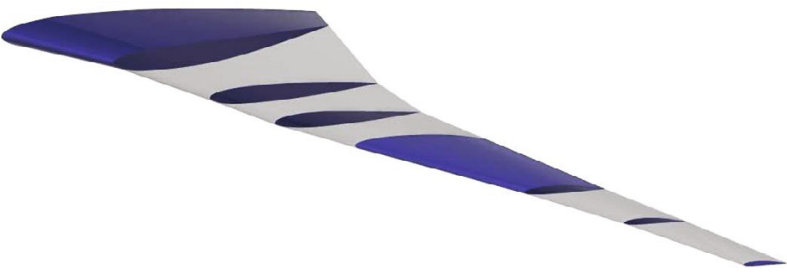

(b)

FIgure 1: A conventional wing with control surfaces (a) [8] and a morphing wing with flexible ribs (b). Control surfaces: (1) winglet, (2) low speed aileron, (3) high speed aileron, (4) flap track fairing, (5) Kruger flaps, (6) slats, (7) three slotted inner flaps, (8) three slotted outer flaps, (9) spoilers, and (10) spoilers-air brakes.

TABLE 1: Comparison between a conventional wing and a morphing wing aircraft.

\begin{tabular}{|c|c|c|}
\hline & Conventional wing aircraft & Morphing wing aircraft \\
\hline $\begin{array}{l}\text { Morphing devices or } \\
\text { mechanisms }\end{array}$ & $\begin{array}{l}\text { Control surfaces: slats, slotted flaps, winglets, } \\
\text { retractable landing gear [2] }\end{array}$ & $\begin{array}{l}\text { Leading edge (LE) } \\
\text { Trailing edge (TE) } \\
\text { Global (LE+TE) }\end{array}$ \\
\hline Features & Discrete, hinged, jointed & Continuous, flexible, elastic, jointless \\
\hline Cons & $\begin{array}{l}\text { (i) More drag [3] } \\
\text { (ii) Flow separation } \\
\text { (iii) Airframe noise [4] }\end{array}$ & $\begin{array}{l}\text { (i) Overconsumption of power [5] } \\
\text { (ii) Practicality of smart materials } \\
\text { (iii) Mostly applied to small aircrafts } \\
\text { (iv) Scalability (extending UAV to long range aircraft) } \\
\text { (v) Aeroelastic complexities due to higher degree of freedom } \\
\text { associated with morphing }\end{array}$ \\
\hline Pros & $\begin{array}{l}\text { (i) Reliability } \\
\text { (ii) functionality }\end{array}$ & $\begin{array}{l}\text { (i) Minimized flow separation } \\
\text { (ii) Improved lift/drag } \\
\text { (iii) Increased range [6] } \\
\text { (iv) Reduced fuel consumption } \\
\text { (v) Reduced airframe noise [7] } \\
\text { (vi) Drag minimization } \\
\text { (vii) Expanded operational envelope } \\
\text { (viii) Multifunctional } \\
\text { (ix) No weight penalties of control surfaces } \\
\text { (x) Reduced assembly complexities and costs that otherwise from } \\
\text { control surface deployment mechanisms }\end{array}$ \\
\hline
\end{tabular}

as camber morphing. Camber, in a broad sense, represents the curvature, convexity, or asymmetry of an airfoil between the leading and trailing edge, and continuously varying the camber rate has benefits in terms of control, lift distribution, and airframe noise.

\section{Types of Morphing Mechanism Implementation}

The design and implementation of a camber morphing wing for wind tunnel or actual flight testing is a challenging task since the topology of the internal structure is to be rigid enough to sustain the structural deformation as well as the aerodynamic loading, while being flexible enough to be deformed in morphing directions. Thus, the design and implementation of morphing wings requires investigating not only the morphing capabilities of the mechanism but also the actual manufacturability and practical implementa- tion corresponding to flights-the cause and effects of morphing in flights. Therefore, this paper focuses on the informative guidelines of various designs and the principles behind these morphing mechanisms, to allow researchers in the related field to choose an appropriate approach in their designs and have better directions based on the critical review of various morphing mechanisms.

During the process of designing a morphing mechanism, various design parameters are to be considered-provided by advanced materials and design and optimization strategies. The optimization tools used, as classified by $\mathrm{Li}$ and others [10], are topology optimization algorithms, parameter optimization, and evolutionary optimization, out of which topology optimization tools are frequently used to design camber morphing mechanisms. The objective function to be minimized can be the structural weight, energy for shape reconfiguration, control authority, or aerodynamic characteristics, while the design variables are the shape variables 


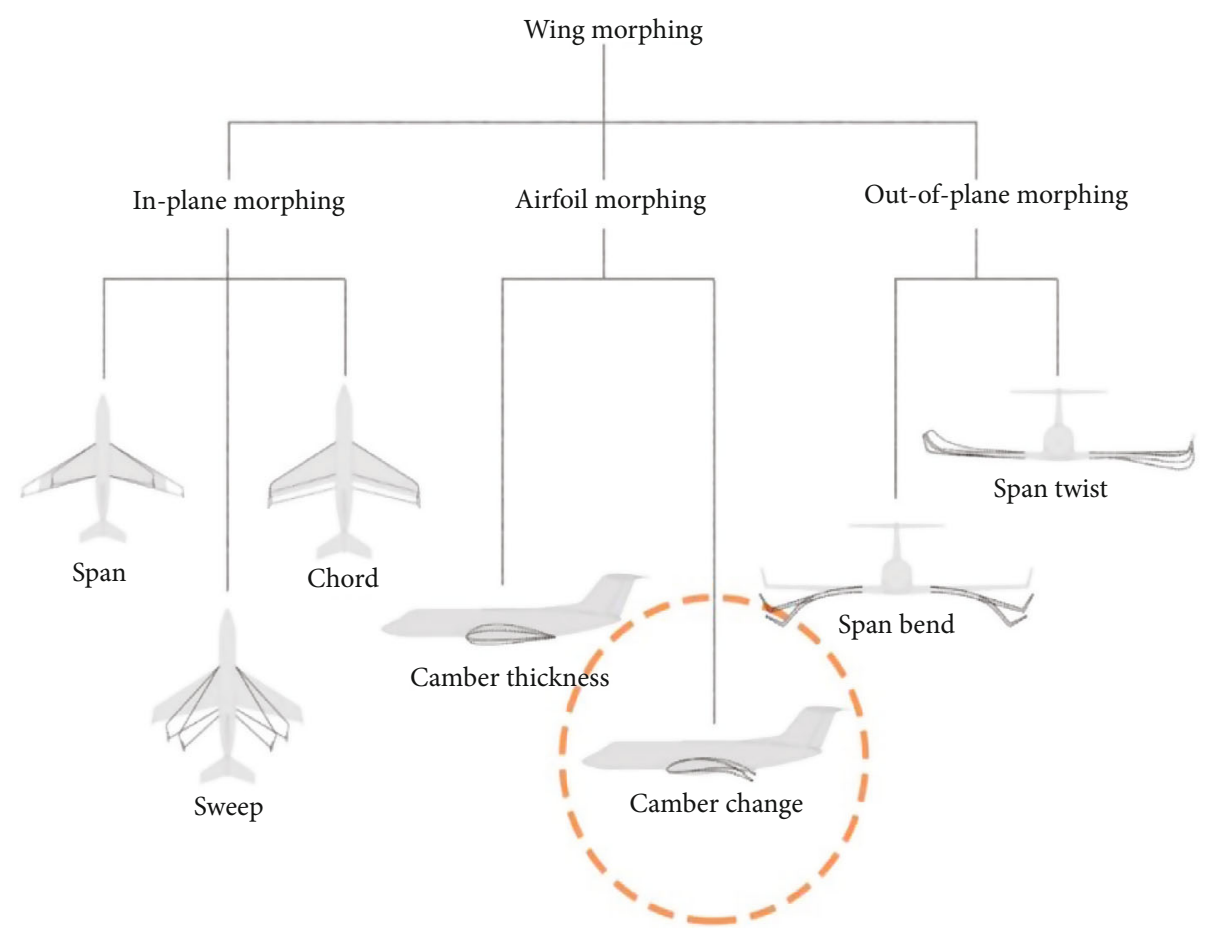

FIgURE 2: Different types of wing morphing [9].

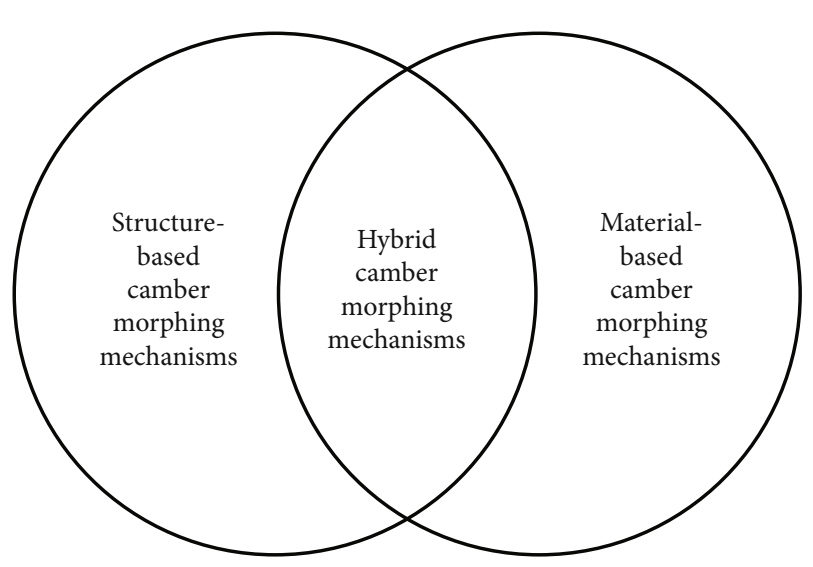

FIGURE 3: Different categories of camber morphing mechanisms.

(like the control points on the boundary of airfoil) and structural variables (location of actuators, etc.).

On the basis of mechanism's synthesis methodology, tools used, and conceptual design, this paper classifies camber morphing mechanisms into three categories: (1) structure-based, (2) material-based, and (3) hybrid (as shown in Figure 3). The classification is based on how shape morphing is conceptualized and physically implemented: whether it is the internal structural layout, the material characteristics, or some combination of both-a hybrid-that plays a major role in morphing the wing. In the next few sections, different camber morphing mechanisms are highlighted under each of the categories.

2.1. Structure-Based Camber Morphing Mechanisms. We consider structure-based morphing mechanisms when only the internal structural layout, independent of the material used, is responsible for geometrically changing the camber of the airfoil. One of representative morphing camber systems developed by Communier et al. [11] for instance is structure-based. When actuated by the control arms connected to the rods at the leading and trailing edge, as shown in Figure 4, a torque is generated so that the rib structure performs small rotations and rotates at the same rate in each slit. The behavior of each slit is similar to that of a pivot, and these rotations generate the morphing motion. The concept was tested, and the results showed improved aerodynamic performance as compared to a nonmorphing system, but with a lower maximum shape-changing capability.

Adaptive variable camber wing (AVCWing) design [12] features a double rib sheet (DRS) - a structural geometry of a circular ear and a semicircular groove attached together. The structural layout, as seen in Figure 5, has multiple DRS sections connected at the point of contact between the semicircular groove on one side and a circular earpiece on the other side (of the adjacent section). The actuation force transmits at this point of contact while the shape changes by the rotation of the sections. Actuators are distributed chord-wise, and the rotation of the sections creates grooves on the surface of the airfoil and the wing. A smoothness analysis and the investigation of aerodynamic characteristics of the morphing concept showed improved flight efficiency and the grooves to have little effect on the aerodynamic performance of the wing at low speeds.

Chanzy and Keane [13] modelled a compliant wing concept to achieve greatest roll control-featuring a wing cover design, as shown in Figure 6, where an open-slot trailing edge with ribs attached to the spar but detached at the trailing-edge, allowing the upper and lower surfaces to slide over 


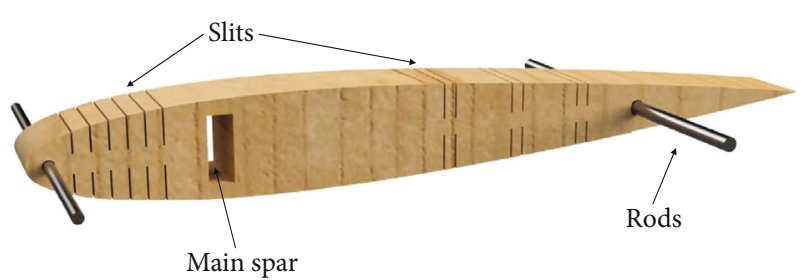

FIGURE 4: Rib structure of the vertically slitted design concept.

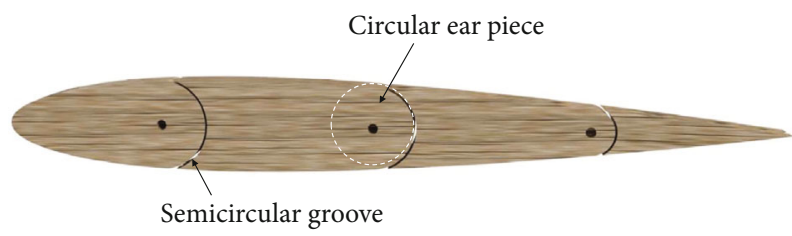

FIGURE 5: Camber morphing AVCWing design with multiple DRS sections.

each other. A series of slotted mechanisms in the trailing edge with one being linked to an actuator mechanism controls morphing. A finite element method (FEM) analysis and computational fluid dynamics- (CFD-) based optimization design search was carried out to gain greatest roll control. The thickness of the morphing surface material was optimized at two inner points for overall lift coefficient of the deformed shape, using MATLAB, ABAQUS- and the full potential CFD code to construct a response surface surrogate model of the effect of geometry changes on lift. A prototype using a multiturn servomotor with digital control driving a worm-and-nut system as an actuator mechanism, a glassfiber-clad polystyrene foam as the wing skin, 3D-printed SLS-nylon inserts as ribs, and a carbon-fiber spar was tested in a wind-tunnel and in flight, showing improved lift-todrag ratio compared to a standard wing fitted with conventional ailerons.

Multiunit flexible rib mechanism [14] is another structure-based morphing mechanism where the actual morphing between the two designated states (NACA 0012 airfoil baseline configuration to a target configuration closest to NACA 6412 airfoil geometry) relies on the flexibility of its structure-flexibility that comes from a multiunit structural design comprising of basic unit subassemblies connected together by revolute joints. Except for the trailing edge subassembly, each subassembly is composed of two identical outer parts and one embedded inner part. All inner and the outer parts have a unique shape, specific to the position of the subassembly along the rib, to allow the inner part of the adjacent subassembly to be embedded into the inner part of neighboring subassembly and so on. The structure of this multiunit flexible rib is shown in Figure 7. A functional wooden prototype, actuated by a rocker slider system, was manufactured, and flight tested, in addition to on-ground static loading tests conducted to test its morphing abilities.

The use of corrugated structures inside the core of morphing sections to vary the camber of the wing was demonstrated by Yokozeki et al. [15] depicted in Figure 8. The concept is classified as structure-based as it is the radius and thickness of the corrugation (determined by trial and error) that results in the downward deflection of the morphing sections. Both the leading edge and trailing edge morphing sections, placed before and after the fixed section, have corrugated structures glued to the upper skin while the lower skin is covered with a flexible sheet. Two wires each connected to a pulley and designated a roll-up ratio, form a set (operated with a motor at both the leading and the trailing edge). Morphing and deformation under aerodynamic loads were numerically simulated and experimentally measured in a wind tunnel using a prototype fabricated with carbon fiber-reinforced polymer (CFRP) laminates for the corrugations and the upper skin. The model demonstrated smooth deformations during actuation at wind speed of $20 \mathrm{~m} / \mathrm{s}$ [16].

Maki [17] developed and tested a multislotted variable camber mechanism where a designated section of the base airfoil (NACA 4409) was divided into five overlapping elements (four slots) that can be closed or spread to vary the camber depicted in Figure 9. The spar runs through the fixed third element while the rest move backward or forward around it to open the slots in a global manner. The morphing mechanism, connecting to the elements, is a linkage system and a control horn driven by a single motor. The morphing concept was established to quantify its aerodynamic benefits in terms of improved STOL: short take-off and landing performance, and the wind tunnel tests showed improved lift characteristics and a dramatically extended stall margin as compared to a conventional control surface (flap and slat) configuration wing. The flow field around the multislotted airfoil was also explored by Kuya et al. [18] using two-dimensional and three-dimensional Reynolds-averages Navier Stokes (RANS) computations for tip vortices and flow separation.

The morphing structural concept, developed for adaptive trailing edge (ATE) box ribs, in the framework of Smart Intelligent Aircraft Structures (SARISTU) project [19], is another example of a structure-based camber morphing mechanism. The finger-like, segmented rib design has a single degree of freedom and was designed to morph the wing shape at the trailing edge to compensate for the fuel burning weight reductions in cruise condition and maximize aerodynamic performance. The rib structural layout consists of two linking elements that rotate the four plates according to specific gear ratios. The segment/plate is connected by hinges like an articulated chain of consecutive segments, where the first plate connects ATE to the rest of the wing structure, and all other blocks freely rotate around the hinges located parallel to the airfoil camber line. A transfer of the rib's kinematic to an overall trailing edge structure was proposed, by means of a multibox arrangement, and the application of ATE as a morphing flap and a morphing aileron investigated $[20,21]$. Aero-servo-elastic impact of a full-scale morphing wing trailing edge on a CS-25 category aircraft is presented in $[22]$.

2.2. Material-Based Camber Morphing Mechanisms. A material-based camber morphing mechanism features material anisotropy and tools like material topology optimization 


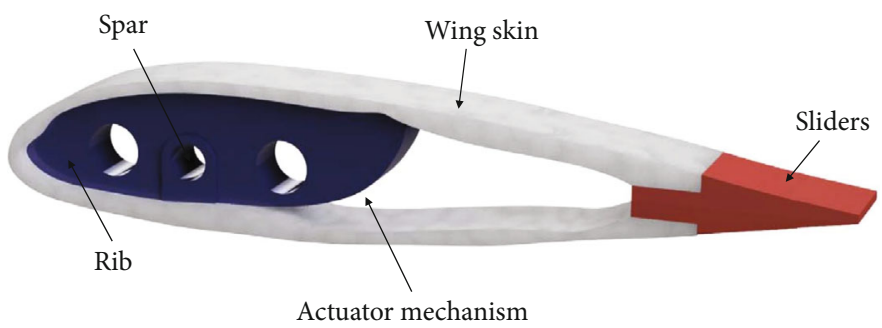

Figure 6: Open slot trailing edge wing cover design concept.

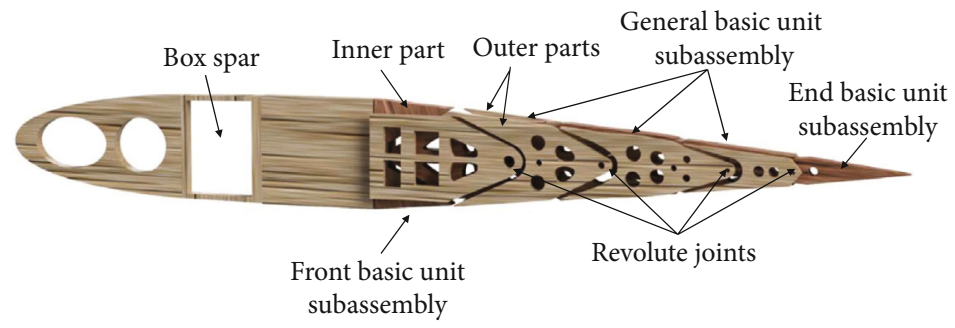

FIgURE 7: Multiunit flexible rib camber morphing design concept.

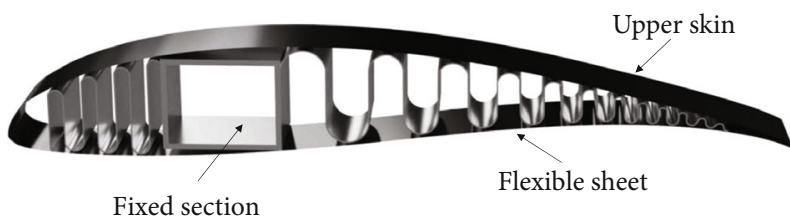

FIGURE 8: Corrugated structures camber morphing design concept.

to distribute the material on the structural layout. The camber morphing concept of distributed compliance and electromechanical actuators, tested on an AM drone to achieve control moments [23] is an example of a material-based camber morphing mechanism depicted in Figure 10. The wing's ribs were designed to exploit the material anisotropy and strength of the composite material, achieved by additively manufacturing ribs with CFRP and polyamide- 12 . The push-pull movements of the actuator rod deflect the trailing edge, and individually controlled actuators are distributed along the span to change lift distribution for roll control. The drone parts were printed based on the additive fusion technology and flight tested, showcasing superior maneuverability and achieving maximum roll rates of up to $240^{\circ}$ s. Other examples include VCCW, MACWing, and Smart Wing.

Variable camber compliant wing (VCCW) developed by Air Force Research Laboratory (AFRL) had compliant mechanisms at both the leading and trailing edge which were synthesized using a material-based topology optimization approach and actuated by a single, linear actuator to achieve a $6 \%$ camber change from $2 \%$ to $8 \%$. A threedimensional shape change was implemented by distributing the compliant mechanisms spanwise and controlling the camber variations independently with the actuators. A prototype of this morphing concept-with a rigid main spar and a seamless, continuous skin fabricated from a single piece of nonstretchable composite-was wind tunnel tested to comprehend the flow around the flexible wing and the surface deformations under aerodynamic loading.

The mission adaptive compliant wing (MACWing) [6], developed by FlexSys Inc., highlight is their adaptive structure trailing edge flap system designed to maximize the laminar boundary layer over a wide lift coefficient range-potentially extend the range of high altitude, longendurance aircraft by $15 \%$. The flap can deflect $\pm 10^{\circ}$ where morphing of the upper and lower surfaces comes from the elastic nature of its underlying structure, consisting of intermediary mechanisms that distribute localized actuation throughout the structure. The composite materials for the complaint structure were customized using a material topology optimization method, to enable flap deformations within material's yield strength. The design and optimization tools used, considered shape variables and structure variables like the external loading, actuator force and displacement, morphing shape error, overall system weight, fatigue, buckling forces, package constraints, and system complexity. The final compliant structure design manufactured allowed a seamless transition between the fixed and flapped portions of the wing and showed a $30^{\circ}$ s flap deflection when flight tested on an aircraft.

The Smart Wing developed in the DARPA/AFRL/NASA Smart Wing Program has a trailing edge control surface system, capable of deflecting up to $10^{\circ}$ [24], with a silicon skin and honeycomb core at the trailing edge that gives the flexibility needed to create changes in camber. 10 individual segments at the trailing edge directly attach into the wing structure-a connection mechanism that allows shapememory alloy (SMA) torque tubes to transfer high degree torque to the structure. These segments are structurally flexible and bend and twist in the desired direction when driven by an ultrasonic piezoelectric motor via an eccentuator-a kinked rod that converts motor's rotary motion into a linear force along the chord. Each motor was also fitted with a gearbox of 5:1 gear ratio for desired torque output, and 


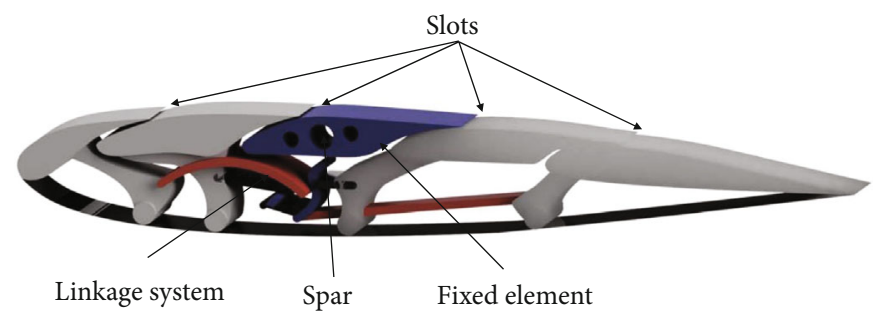

FIGURE 9: Multislotted variable camber design concept.

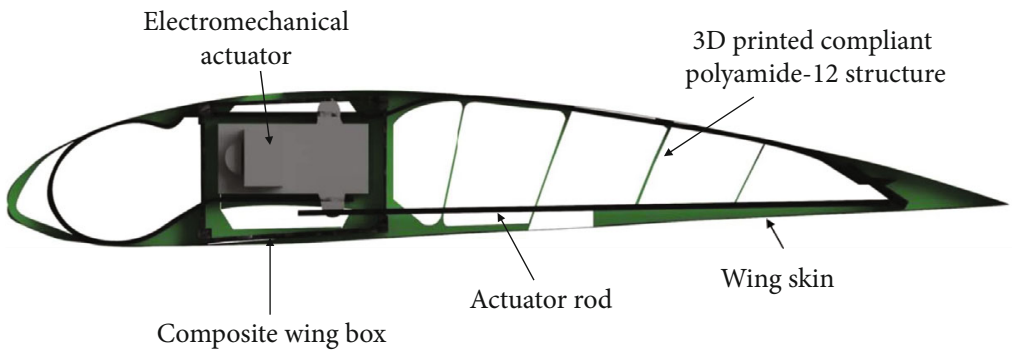

FIgURE 10: AM drone camber morphing design concept.

the system showed large deflections when fitted on a UAV and tested in a wind tunnel [25].

2.3. Hybrid Camber Morphing Mechanisms. Hybrid camber morphing mechanisms possess characteristics individually associated with a structure-based or a material-based morphing mechanism, combined. Examples include concepts that manipulate material characteristics to morph a certain part of the section while employing some distinctive structural elements to morph other parts or use smart materials as actuators on an internal structural design based on a topology optimization method.

The variable camber morphing wing designed by Zhang et al. [26] is categorized as a hybrid. There are monolithic compliant mechanisms present at its leading and trailing edges that when actuated by a linear motion change the outer shape drawn by the laminated skin shown in Figure 11. The tools used to design this morphing wing include optimizing the driving forces by a genetic algorithm and designing the compliant mechanisms by a meshlessbased topology optimization method for hyperelastic structures (solid isotropic material with penalization-SIMP Method), where the objective function is to maximize the output displacement, while the design variable is the nodal density (material) [27]. The materials used to manufacture the prototype include spring steel and glass-fiber reinforced polymer composites for the laminated skin, aluminum for stringers, a flexible polylactic acid (PLA) material for 3D printing the compliant mechanism, and a linear stepper motor through a leadscrew as the actuator. The demonstrator showed deflections around $27^{\circ}$ at the leading edge and from $-8^{\circ}$ to $40^{\circ}$ at the trailing edge.

The NOVEMOR aircraft wing, with a droop-nose morphing wing-tip (developed by the German Aerospace Centre, DLR), and a camber morphing wing section (developed by Politecnico di Milano, PoliMi), is another example

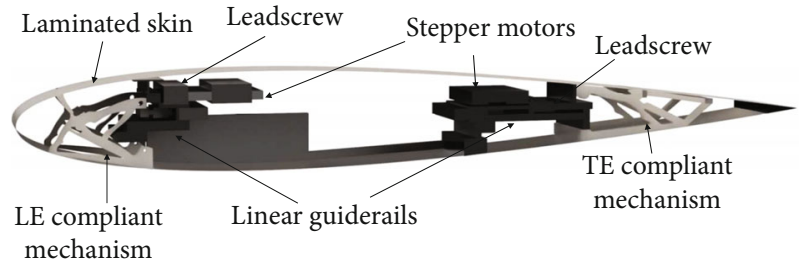

FIGURE 11: Laminated skin and variable camber morphing wing design concept.

of a hybrid mechanism [28]. Although earlier kinematical concept of smart droop-nose consists of a main lever and interconnecting struts [29], DLR's Droop-Nose-with a target $2^{\circ}$ droop deflection-features a flexible and tailored fiberglass skin, designed by continuum-based topology optimization and driven by internal compliant mechanisms fabricated from superelastic nickel titanium and aluminium alloys [30]. The thickness distribution of the skin was computed employing an optimization tool developed for 3D wing geometries, where the objective function accounts for both the flexibility and stiffness requirements of the skin, whereas a 2D continuum gradient-based topology optimization with a solid isotropic material with penalization (SIMP) method, material model, was used to design compliant mechanisms. On the other hand, the compliant mechanisms for PoliMi's leading and trailing edge morphing devices were designed using two design tools: PHORMA (Parametrical sHapes for aerOdinamic and structural Modelling of Aircrafts) and SPHERA (Synthesis of comPliant mecHanisms for EngineeRing Applications), 3D printed and assembled into a wingbox for wind tunnel testing [31]. The design approach is based a two-level optimization procedure described in [32, 33]. Additionally, an advanced droopnose morphing leading edge concept for implementation onto a natural laminar flow wing of a regional aircraft is also being developed $[34,35]$. 


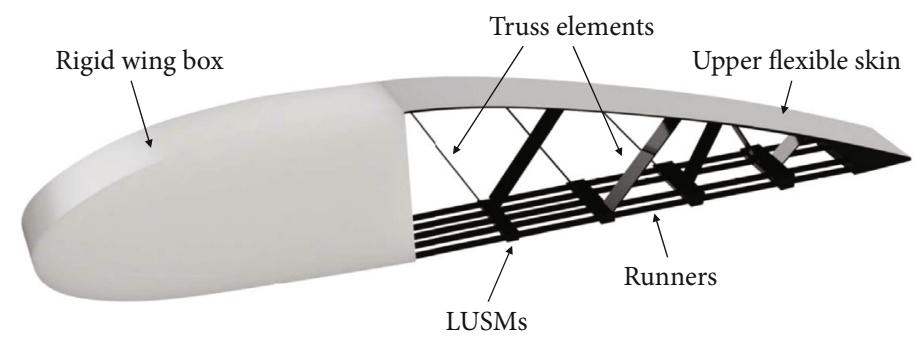

FIgURE 12: Multiple DOF camber morphing design concept.

Wu et al. [36] proposed a multiple degrees of freedom camber morphing concept, where the multiple degree-offreedom (DOF) nature allows generation of different morphing configurations illustrated in Figure 12. The internal structural layout comprises of a rigid wing box and multiple compliant truss elements. One side of the truss element is hinged to the upper flexible skin of the trailing edge while the other side is driven by independently controlled compliant runners, powered by an electrical actuation system-a linear ultrasonic motor (LUSM) based on piezoelectric ceramics. Morphing is achieved by fixing one or more runners at the lower surface of the trailing edge and allowing the truss elements to slide along these runners through the LUSMs; the movement of the truss elements thus bends or straightens the structure. The morphing process, aerodynamic benefits, and the loading capacity of the proposed design were tested using carbon fiber composite airfoil prototypes and validated by computational analysis.

The CHIRP smart airfoil [37] is another hybrid camber morphing mechanism, designed by concurrent optimization of structural and aerodynamic parameters to maximize roll controllability and minimize drag. The structure has a semimonocoque construction, with a rigid $\mathrm{D}$-spar, a parameterized, Voronoi-geometry-based intermediate section, and a compliant trailing edge section with corrugation at the lower skin. Smart materials-piezoelectric patches and dielectric elastomers-are integrated into the structure and used as actuators to deflect the trailing edge illustrated in Figure 13. The Voronoi-based geometry of the inner structural layout was optimized using a gradient-free optimization algorithm, based on the covariance matrix adaptation evolution strategy [38]. The resulting optimized wing geometry was manufactured using fiber-reinforced plastics (GFRP, CFRP) and the aerodynamic and structural performance investigated numerically and experimentally showing a high aerodynamic efficiency. The aeroelastic response assessed through wind tunnel tests [39] produced rolling moment coefficients between 0.03 at $10 \mathrm{~m} / \mathrm{s}$ and 0.021 at $30 \mathrm{~m} / \mathrm{s}$. A prototype of the CHIRP smart airfoil was also flight tested on a UAV demonstrating sufficient controllability and maneuverability of the plane being produced exclusively through morphing. This design was also extended to a span-wise varying camber morphing wing [40] with electromechanical actuators.

Woods and Friswell [41] introduced a biologically inspired fish bone active camber concept, with a thin chordwise bending spine, and stringers branching off like a fish's ribs, to connect it to a pretensioned elastomeric matrix com-

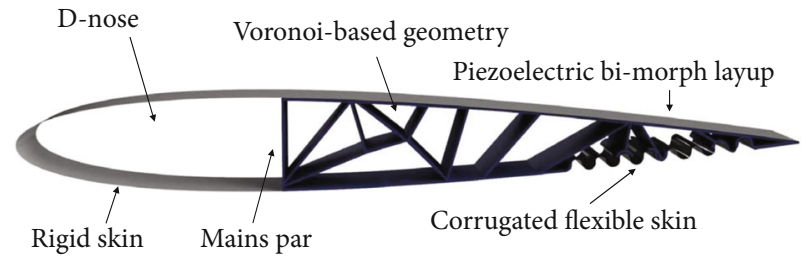

FIGURE 13: CHIRP smart airfoil design concept.

posite (EMC) skin surface. The stringers maintain the airfoil thickness by supporting the skin at a constant distance from the spine. The deflections are induced by the bending moments on the spine, through an antagonistic tendon drive system mounted inside the D-spar, with one end of the tendon anchored to the trailing edge and the other wrapped around a spooling pulley, connected to the actuator through a nonbackdrivable mechanism such as a worm gear illustrated in Figure 14. A prototype of the FishBAC concept, $3 \mathrm{D}$ printed out of $\mathrm{ABS}$ plastic, was tested in a wind tunnel, and a comparative experimentation with traditional trailing edge flaps showed increased lift-to-drag ratio [42]. The nonbackdrivable mechanism and the implementation of tensioned antagonistic tendon drive system were also tested [43], whereas the initial design, analysis, and prototyping of the FishBAC concept were performed using a onedimensional analytical model based on Euler-Bernoulli beam theory, Rivero et al. [44] addressed the twodimensional structural formulation for the concept, based on Kirchhoff-Love plate theory, and the three-dimensional deflections, based on Mindlin-Reissner plate theory [45].

A morphing wing box concept consisting of morphing and fixed sections is proposed [46]. The actuation system consists of two oblique cams, located at 0.25 and 0.47 of the chord length that convert horizontal, spanwise motion into vertical motion. The vertical movement is controlled by a mechanical equilibrium between shape memory alloy (SMA) wires and gas springs being pulled in opposite directions that in turn adjusts the airfoil shape to obtain one of the 35 optimized airfoils illustrated in Figure 15. Numerical simulations and tests were performed to design and validate the morphing wing control system $[46,47]$, and a full-scale model was manufactured using aluminum alloy for internal structure, carbon fibre composite materials for upper, adaptive surface, and electrical actuators installed in place of smart materials. Static and aeroelastic behavior of the wing was studied [48], and an experimental validation of the optimized wing geometry is presented in [49]. 


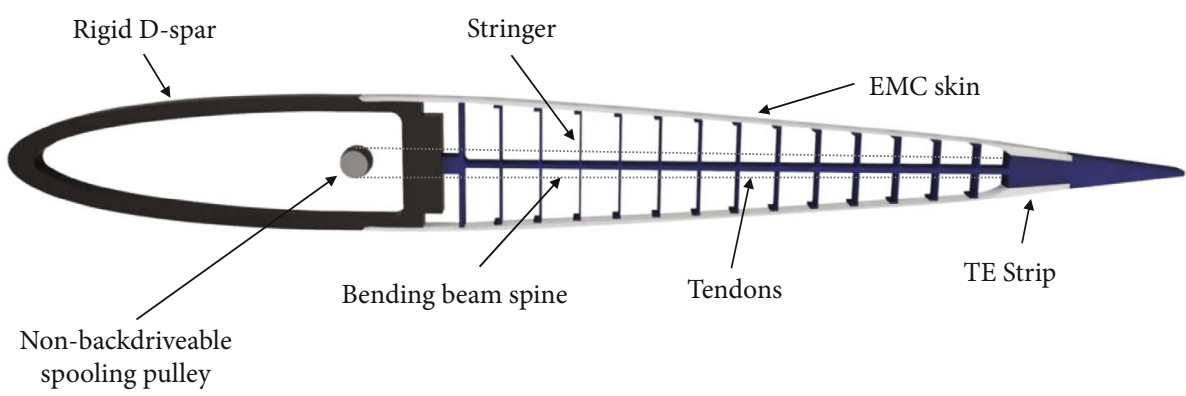

Figure 14: FishBAC concept.

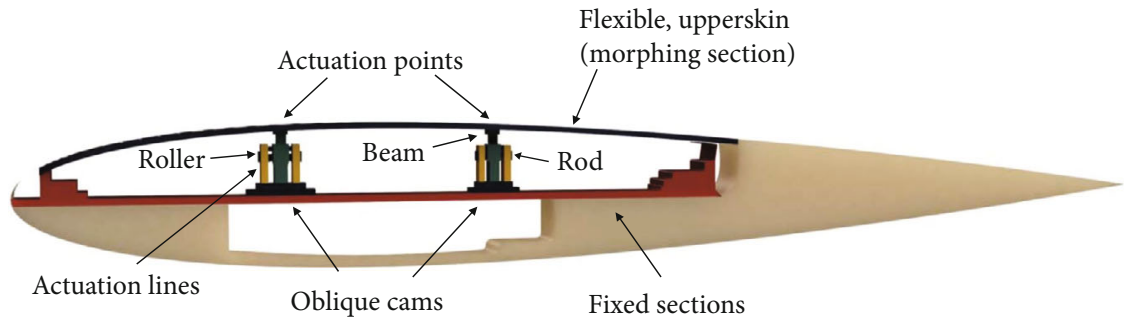

Figure 15: Morphing wingbox concept.

2.4. Other Camber Morphing Concepts. Several designs, applicable to a morphing wing, have been proposed in the literature. Zhao et al., for instance, presented a rigid-body mechanism of prismatic and revolute joints that can morph between a defined set of curves at different positions [50]. Li and $\mathrm{Li}$ [51] conducted a kinematic simulation of their linkage mechanism with two closed loop that morph the trailing edge [52]. Sahin and Yaman [53] introduced a scissorstructural mechanism for the trailing edge of a morphing wing. Ivchenko et al. [54] proposed reconfigurable honeycomb core, based on a network of joints for an adaptive, compliant wing frame morphing concept. However, such concepts did not progress to the manufacturing and testing stage [55-60]. Other unconventional camber morphing concepts that have also been studied include the pseudoflap concept by Xie et al. [61] who investigated the aerodynamic response of a soft material based inflatable actuator embedded in a stiff structure. Li et al. [62] proposed a skin-driven morphing concept using pneumatic artificial muscles (PMAs) embedded in skin. Fishing lines were used to simulate the role of artificial muscles and demonstrate the driving skin mechanism with a morphing angle of $\pm 30^{\circ}$. Zhang et al. [63] designed a cross-shaped honeycomb and distributed actuation morphing concept, implemented with lightweight pressurized telescopic tube actuators embedded in the trailing edge surface with cross-shaped flexible honeycombs filled underneath.

Pressure-adaptive honeycomb materials and fluidactuated morphing has gained a lot of attention recently. Pressure-adaptive honeycomb is a new Federal Aviation Administration (FAA) or Experimental Aircraft Association (EAA) certifiable adaptive material that is being investigated for its application in wing morphing [64]. Pressure-actuated morphing relies on optimally designed cellular structure to generate force when pressurized, where the cell would elon- gate, when the pressure of the fluid is increased and the variations in thickness or length would convert to deflections in desired direction. Vasista and Tong [65] designed the cell shapes of a morphing structure for the trailing edge of a NACA0012 airfoil using a moving isosurface threshold (MIST) topology optimization method. Different cell network architecture with the same number of cell elements was considered, and the results featured arch-like structures that enclose the pressurized fluid that allow elongation along one or two edges. Heo et al. [66] investigated the structural performance and application of compliant cellular cores (chiral, regular, and reentrant hexagonal honeycombs) to passively morphing airfoil. Taguchi et al. [67] tested a passively morphing airfoil model, deforming from a NACA 0012 baseline configuration to a NACA 0024 morphed configuration by dynamic pressure only (without any actuator). The airfoil was fabricated using flexible materials with upper and lower surfaces connected by spokes.

\section{Summary}

A summary of recent state-of-the-art technologies of the camber morphing mechanisms and their concepts and approaches is presented in Table 2, highlighting the mechanism design philosophy and the extent to which the performance of the morphing concept was assessed. The concepts were categorized based on the design features and the tools and methods employed to solve the mechanism design problem. While some of the structure-based mechanism designs presented are in the level of proof-of-concept, most material-based and hybrid morphing mechanisms were carefully synthesized using optimization tools or designed in response to the design drivers-roll control, aerodynamic performance, etc. A variety of different actuators was used ranging from linear, electromechanical, and smart material 
TABLE 2: Summary of camber morphing mechanisms.

\begin{tabular}{|c|c|c|c|c|c|c|c|c|c|c|}
\hline Concept & Approach & $\begin{array}{l}\text { Morphing } \\
\text { section } \\
\text { (deflection) }\end{array}$ & Purpose & Numerical & Prot. & Actuator & $\begin{array}{l}\text { Investigatio } \\
\text { Reynolds } \\
\text { number } \\
\left(10^{5}\right)\end{array}$ & $\begin{array}{l}\mathrm{n} \\
\mathrm{WT}\end{array}$ & Speed & FTB \\
\hline \multicolumn{11}{|c|}{ Structure-based camber morphing mechanisms } \\
\hline $\begin{array}{l}\text { Vertically } \\
\text { slitted }\end{array}$ & - & $\begin{array}{c}\text { LE, TE } \\
(4 \%)\end{array}$ & Morphing & $\checkmark$ & $3 \mathrm{D}$ & Servos & 3.9 & $\checkmark$ & $20 \mathrm{~m} / \mathrm{s}$ & $\checkmark$ \\
\hline AVCWing & - & $\mathrm{LE}, \mathrm{TE}\left(7^{\circ}\right)$ & Morphing & $\checkmark$ & $2 \mathrm{D}$ & Servos & $4.5-8.2$ & & $20 \mathrm{~m} / \mathrm{s}$ & $\checkmark$ \\
\hline $\begin{array}{l}\text { Open slot } \mathrm{TE} \\
\text { wing }\end{array}$ & $\begin{array}{l}\text { FEA- and CFD-based } \\
\text { optimization algorithm }\end{array}$ & $\mathrm{TE}$ & Roll authority & $\checkmark$ & $2 \mathrm{D}$ & Servos & - & $\checkmark$ & $24 \mathrm{~m} / \mathrm{s}$ & $\checkmark$ \\
\hline Multiunit rib & - & $\begin{array}{l}\text { LE, TE } \\
(6 \%)\end{array}$ & Morphing & $\checkmark$ & $2 \mathrm{D}$ & Servo & $3.6-7$ & $\checkmark$ & $20 \mathrm{~m} / \mathrm{s}$ & $\checkmark$ \\
\hline $\begin{array}{l}\text { Corrugated } \\
\text { structures }\end{array}$ & - & $\begin{array}{l}\text { LE, TE } \\
\left(40^{\circ}\right)\end{array}$ & Morphing & $\checkmark$ & $2 \mathrm{D}$ & Servos & $5-15$ & $\checkmark$ & $\begin{array}{c}10- \\
40 \mathrm{~m} / \mathrm{s}\end{array}$ & \\
\hline Multislotted & - & Global & STOL & $\checkmark$ & $2 \mathrm{D}$ & - & 6.2 & $\checkmark$ & $20 \mathrm{~m} / \mathrm{s}$ & \\
\hline ATE box rib & - & $\begin{array}{c}\mathrm{TE} \\
\left(30^{\circ}, \pm 10^{\circ}\right)\end{array}$ & Aeroelasticity & $\checkmark$ & $3 \mathrm{D}$ & Servo rotary & - & $\checkmark$ & $\begin{array}{c}0- \\
250 \mathrm{~m} / \mathrm{s}\end{array}$ & \\
\hline \multicolumn{11}{|c|}{ Material-based camber morphing mechanisms } \\
\hline AM drone & - & $\begin{array}{c}\mathrm{TE} \\
(48 \mathrm{~mm})\end{array}$ & $\begin{array}{l}\text { Control } \\
\text { moments }\end{array}$ & - & $3 \mathrm{D}$ & Servos & - & - & - & $\checkmark$ \\
\hline VCCW & $\begin{array}{l}\text { Material-based topology } \\
\text { optimization }\end{array}$ & $\begin{array}{c}\text { Global } \\
(6 \%)\end{array}$ & $\begin{array}{c}\text { Design } \\
\text { validation }\end{array}$ & $\checkmark$ & $3 \mathrm{D}$ & Linear & 10.5 & $\checkmark$ & $\begin{array}{c}25.72 \mathrm{~m} / \\
\mathrm{s}\end{array}$ & $\checkmark$ \\
\hline MACWing & $\begin{array}{l}\text { Continuum material } \\
\text { topology optimization }\end{array}$ & $\begin{array}{c}\mathrm{TE} \\
\left(-10^{\circ}, 40^{\circ}\right)\end{array}$ & Range & $\checkmark$ & $3 \mathrm{D}$ & $\begin{array}{l}\text { Electro- } \\
\text { mechanical }\end{array}$ & $28-33$ & $\checkmark$ & $\begin{array}{c}\text { Mach } \\
0.55 \\
188 \mathrm{~m} / \mathrm{s}\end{array}$ & $\checkmark$ \\
\hline Smart wing & - & $\operatorname{TE}\left( \pm 20^{\circ}\right)$ & $\begin{array}{l}\text { Aerodynamic } \\
\text { performance }\end{array}$ & $\checkmark$ & $3 \mathrm{D}$ & $\begin{array}{l}\text { Ultrasonic } \\
\text { PE motor }\end{array}$ & 18.3 & $\checkmark$ & $\begin{array}{c}\text { Mach } \\
0.3-0.8 \\
103- \\
275 \mathrm{~m} / \mathrm{s} \\
\end{array}$ & $\checkmark$ \\
\hline \multicolumn{11}{|c|}{ Hybrid camber morphing mechanisms } \\
\hline $\begin{array}{l}\text { Composite } \\
\text { material }\end{array}$ & $\begin{array}{c}\text { Meshless topology } \\
\text { optimization for } \\
\text { hyperelastic structures }\end{array}$ & $\begin{array}{c}\operatorname{LE}\left(27^{\circ}\right) \\
\operatorname{TE} \\
\left(-8^{\circ}, 40^{\circ}\right)\end{array}$ & Morphing & $\checkmark$ & $2 \mathrm{D}$ & $\begin{array}{l}\text { Linear } \\
\text { stepper } \\
\text { motor }\end{array}$ & 55.2 & - & $40 \mathrm{~m} / \mathrm{s}$ & \\
\hline $\begin{array}{l}\text { NOVEMOR } \\
\text { aircraft wing }\end{array}$ & PHORMA and SPHERA & $\begin{array}{c}\operatorname{LE}\left(7^{\circ}\right) \\
\operatorname{TE}\left( \pm 10^{\circ}\right)\end{array}$ & $\begin{array}{l}\text { Validation of } \\
\text { design } \\
\text { framework }\end{array}$ & $\checkmark$ & $3 \mathrm{D}$ & Linear & - & $\checkmark$ & $40 \mathrm{~m} / \mathrm{s}$ & \\
\hline $\begin{array}{l}\text { NOVEMOR } \\
\text { droop-nose } \\
\text { wingtip }\end{array}$ & $\begin{array}{l}\text { Continuum gradient- } \\
\text { based topology } \\
\text { optimization with SIMP } \\
\text { and optimization tool }\end{array}$ & $\operatorname{LE}\left(2^{\circ}\right)$ & $\begin{array}{c}\text { Droop } \\
\text { deflection }\end{array}$ & $\checkmark$ & $3 \mathrm{D}$ & Linear & - & $\checkmark$ & $55 \mathrm{~m} / \mathrm{s}$ & \\
\hline $\begin{array}{l}\text { Multi-DOF } \\
\text { truss }\end{array}$ & - & $\begin{array}{c}\mathrm{TE} \\
(1.17 \mathrm{~mm})\end{array}$ & Morphing & $\checkmark$ & $2 \mathrm{D}$ & Servos & $5-15$ & $\checkmark$ & $25 \mathrm{~m} / \mathrm{s}$ & \\
\hline $\begin{array}{l}\text { CHIRP smart } \\
\text { airfoil }\end{array}$ & $\begin{array}{c}\text { Concurrent } \\
\text { aerostructural } \\
\text { optimization }\end{array}$ & $\begin{array}{c}\text { Global } \\
(6 \%) \\
\mathrm{TE}\left( \pm 20^{\circ}\right)\end{array}$ & $\begin{array}{l}\text { Roll control, } \\
\text { drag } \\
\text { reduction }\end{array}$ & $\checkmark$ & $3 \mathrm{D}$ & $\begin{array}{l}\text { Piezo- } \\
\text { electric }\end{array}$ & $1.9-5.6$ & $\checkmark$ & $\begin{array}{c}10- \\
30 \mathrm{~m} / \mathrm{s}\end{array}$ & $\checkmark$ \\
\hline FishBAC & - & $\mathrm{TE}\left( \pm 20^{\circ}\right)$ & Morphing & $\checkmark$ & $3 \mathrm{D}$ & Servos & $2-4$ & $\checkmark$ & $\begin{array}{c}\text { Mach } \\
0.05,9 \\
5-30 \mathrm{~m} / \\
\mathrm{s}\end{array}$ & \\
\hline $\begin{array}{l}\text { Morphing wing } \\
\text { box }\end{array}$ & $\begin{array}{l}\text { In-house code } \mathrm{ABC} \text { and } \\
\text { BFGS algorithm }\end{array}$ & $\mathrm{TE}\left( \pm 20^{\circ}\right)$ & $\begin{array}{l}\text { Morphing } \\
\text { control, } \\
\text { performance }\end{array}$ & $\checkmark$ & - & $\begin{array}{l}\text { Electrical, } \\
\text { SMA }\end{array}$ & $14-28$ & $\checkmark$ & $\begin{array}{c}34- \\
68 \mathrm{~m} / \mathrm{s}\end{array}$ & \\
\hline \multicolumn{11}{|c|}{ Other camber morphing concepts } \\
\hline Rigid-body & & $\mathrm{TE}$ & Design & & & & & & & \\
\hline
\end{tabular}


TABLE 2: Continued.

\begin{tabular}{|c|c|c|c|c|c|c|c|c|c|c|}
\hline Concept & Approach & $\begin{array}{l}\text { Morphing } \\
\text { section } \\
\text { (deflection) }\end{array}$ & Purpose & Numerical & Prot. & Actuator & $\begin{array}{c}\text { Investigatio } \\
\text { Reynolds } \\
\text { number } \\
\left(10^{5}\right)\end{array}$ & WT & Speed & FTB \\
\hline & $\begin{array}{l}\text { Planar shape mechanism } \\
\text { synthesis techniques }\end{array}$ & & & & & & & & & \\
\hline Linkage & $\begin{array}{c}\text { Characteristic spectrum } \\
\text { analysis }\end{array}$ & $\mathrm{TE}$ & Morphing & $\checkmark$ & & & & & & \\
\hline $\begin{array}{l}\text { Scissor } \\
\text { structure }\end{array}$ & & $\mathrm{TE}$ & Morphing & $\checkmark$ & & & & & & \\
\hline $\begin{array}{l}\text { Reconfigurable } \\
\text { honeycomb }\end{array}$ & & & Design & & & & & & & \\
\hline Pseudoflap & & LE & Performance & $\checkmark$ & $2 \mathrm{D}$ & Elastomeric & $0.2-0.5$ & $\checkmark$ & $2-5 \mathrm{~m} / \mathrm{s}$ & \\
\hline Skin driven & & $\operatorname{TE}\left( \pm 30^{\circ}\right)$ & Design & $\checkmark$ & & $\begin{array}{l}\text { Artificial } \\
\text { muscles }\end{array}$ & 15 & & & \\
\hline $\begin{array}{l}\text { Cross-shaped } \\
\text { honeycomb }\end{array}$ & & $\operatorname{TE}\left(15^{\circ}\right)$ & Design & $\checkmark$ & & $\begin{array}{l}\text { Telescopic } \\
\text { tubes }\end{array}$ & & & & \\
\hline $\begin{array}{l}\text { Arc-like, } \\
\text { cellular }\end{array}$ & MIST optimization & $\mathrm{TE}$ & Cell design & & & $\begin{array}{l}\text { Pressurized } \\
\text { fluid }\end{array}$ & & & & \\
\hline Cellular core & & Global & $\begin{array}{l}\text { Investigate } \\
\text { properties }\end{array}$ & & & Passive & & & & \\
\hline $\begin{array}{l}\text { Passive } \\
\text { morphing } \\
\text { airfoil }\end{array}$ & & $\mathrm{TE}$ & Morphing & $\checkmark$ & $2 \mathrm{D}$ & $\begin{array}{l}\text { Dynamic } \\
\text { pressure }\end{array}$ & 1.78 & $\checkmark$ & $13.1 \mathrm{~m} / \mathrm{s}$ & \\
\hline $\begin{array}{l}\text { Morphing rib } \\
\text { flap and aileron }\end{array}$ & & $\begin{array}{c}\mathrm{TE} \\
\left(30^{\circ}, \pm 10^{\circ}\right)\end{array}$ & $\begin{array}{l}\text { Morphing } \\
\text { flap morphing } \\
\text { aileron }\end{array}$ & $\checkmark$ & $3 \mathrm{D}$ & Rotary & & $\checkmark$ & & \\
\hline
\end{tabular}

Morphing section (deflection) in (\%) for change in camber rate; $\left({ }^{\circ}\right)$ for maximum deflection angle; and (mm) for peak-to-peak TE deflection. LE: leading edge; TE: trailing edge; Prot.: prototype; WT: wind tunnel testing; FTB: flight test bed.

(shape memory alloy, SMA, and piezoelectric) based on dynamic pressure or pressure based. Physical twodimensional or three-dimensional models of these were fabricated and tested in flight or in a wind tunnel. The performance factors typically investigated in the numerical and experimental analysis of these works are however limited to assessing the structural integrity and the aerodynamic performance of the morphing concepts. A majority of these works provide insufficient data for aerodynamic benefits associated with implementing morphing at different flight conditions such as take-off, cruise, and landing; the energy requirements, i.e., the resources required to morph the structure; morphing control; actual weight; and fatigue failure of the morphing concepts. External literature comparing the overall benefits and feasibility of implementing morphing mechanisms onto a wing [68], especially at similar flight conditions, Mach number, Reynolds number, and angle of attack, would need to be considered.

\section{Discussion}

Although review articles about the different types of morphing wings have been written [69], a review of camber morphing concepts, especially in terms of their morphing mechanisms, is not available. Therefore, in this paper, we attempt to address the camber morphing concepts for implementation in particular. Most morphing mechanisms modify the camber rate through the deflection of either the trailing-edge or the leading-edge sections, and selecting the concepts that had entered the testing stages, this paper categorizes the camber morphing mechanisms into three categories. While the design and implementation of camber morphing mechanisms using smart materials has been a common practice [70], they are out of scope in this paper; as an efficient smart material only, camber morphing concept is rarely seen. Additionally, based on experimentation, it was found that smart material actuators show low frequencies and high operating temperatures which make them challenging to be considered for practical implementation [46].

In evaluating the different camber morphing mechanism, a thorough assessment of their performance seems to be the only plausible evaluation criteria. Thus, by taking into account the breath of details covered during testing and implementation, the authors attempt to highlight a few noteworthy design practices. It is noted that only the MACWing and the Smart Wing were flight tested within the speed range of $100-275 \mathrm{~m} / \mathrm{s}$, greater than Mach. 0.3 , that shows that most of other concepts may not be suitable to fly at high altitude and speeds. Although absence of data on the performance of these mechanisms at higher Mach numbers does not necessarily mean that these concepts are not suitable 
for higher speeds, it makes it unfeasible to make an accurate comparison to evaluate mechanisms' performances.

In terms of their design approach, the compliant mechanisms underlying MACWing were based on a continuum material topology optimization method, while other concepts flight tested like VCCW used a material-based topology optimization framework and CHIRP smart airfoil-a multidisciplinary concurrent optimization of aerodynamic and structural parameters. The approach adopted by other concepts in their designs is shown in Table 2. In fact, optimizing the morphing structure using topology optimization methods has been a common practice, and as categorized in [71], the optimization-based techniques used in designing morphing wing compliant mechanisms can be broadly classified into two categories: load-path representation method and classical density-based topology optimization method. MACWing and CHIRP smart airfoil discussed earlier fit into the first category while composite material morphing wing concept is an example of the latter category.

Topology optimization design approach offers several advantages-initial structural topology does not need to be presumed, reductions in structural weight, etc. However, using these tools to design an adaptive structure can make the process of designing a morphing wing mechanism computationally expensive, depending on whether the optimization is a single or multivariable problem. Furthermore, functional mechanisms based on simple but effective mechanism like FishBAC, corrugated structures, or multi-DOF truss concepts can be seen to perform well with trailing edge deflection of up to $45^{\circ}$ (calculated for multi-DOF truss), at wind speeds up to $40 \mathrm{~m} / \mathrm{s}$ (corrugated structures). It is also noted that two tools-PHORMA and SPHERA-were developed by POLIMI during the NOVEMOR project and employed for aero-structural shape optimization to design the morphing concept [72]. Of which, PHORMA with its analytical basis is said to compute faster. Although more validation studies are required, with such tools at our disposal, there is a potential to reduce the computational cost of optimizing the topology of morphing wing structure.

The category of camber change is classified under airfoil morphing and can be seen to be interpreted as twodimensional-with morphing prototype implementation on either a two-dimensional airfoil level or a continuous, unaltered, spanwise stretch of the two-dimensional airfoil level. However, it is interesting to note that a number of concepts were designed and tested on a three-dimensional wing level as well. The significance of considering the implications of camber morphing onto a wing level, a three-dimensional wing, is to be highlighted because implementation of a twodimensional morphing mechanism design to a finite-length three-dimensional wing affects both the aerodynamic and structural calculations [37]. Thus, both the differences in wing structural properties as well as the geometric variations in span-wise direction would need to be accounted for. Among the three-dimensional concepts investigated, NOVEMOR aircraft concept designs and tests for the entire wing from root to wingtip and AM Drone, VCCW, MACWing, Smart Wing, CHIRP Smart Wing, and FishBac also test a three-dimensional prototype.
With regard to the morphing abilities, in terms of the deflection angle, composite material camber morphing concept was seen to deflect $27^{\circ}$ at the leading edge and from $-8^{\circ}$ to $40^{\circ}$ at the trailing edge, almost as high as the trailing edge deflection angle of FlexSys Inc.'s MACWing $-10^{\circ}$ to $40^{\circ}$ (however, while MACWing prototype was tested in a wind tunnel and in flight, performance of composite camber morphing concept was validated numerically). Corrugated structure morphing concepts also deflect up to $40^{\circ}$, and the multi-DOF truss morphing concept is said to deflect $1.17 \mathrm{~mm}$ starting at $0.42 \%$ chord length which is about $44.6^{\circ}$. FishBAC, morphing wingbox, and smart wing all deflect $\pm 20^{\circ}$ at the trialling edge, whereas the NOVEMOR aircraft wingtip can deflect $2^{\circ}$ while the wing section from the root to the tip shows a $7^{\circ}$ deflection at the leading edge and $\pm 10^{\circ}$ deflection at the trailing edge. Only VCCW and CHRIP Smart Airfoiland multiunit rib concepts were said to be able to morph the camber by $6 \%$, changing the camber in a global manner from baseline configuration, and amongst them, only VCCW was tested at a high Reynolds number (around 3 million). Concepts wind tunnel tested in a high Reynolds number $\left(>10^{6}\right)$ regime include VCCW, smart wing, morphing wing box, and MACWing, while the rest were tested using high-fidelity computational methods: ANSYSFluent, at the stated Reynolds number.

Lastly, it is noted that the observations highlighted may have been limited in their testing conditions (loading, Reynolds number, angle of attack etc.) and implementation stages-as only so much can be inferred about the reliability and maintainability of these concepts to offer a clear, wellacknowledged recommendation. The literature on camber morphing designs and design methodology far outweighs the studies about fabrication of morphing concepts.

\section{Conclusion}

With material advancements, alternative energy sources, and efficient propulsion systems coming to light, a compatible, ready to manufacture morphing wing concept is essential to the design of a new generation of aircrafts. Morphing wing technology has the potential to be competitive by optimizing wing shapes corresponding to the aerodynamic performance to reduce the operating costs and make the aircraft more energy efficient and environment friendly. Both Airbus and Boeing are already developing camber morphing devices for their aircrafts, Airbus-320 and Boeing 78710 [49]. In light of reviewing the available camber morphing concepts, this paper classified these mechanisms into three categories based on their design and synthesis methodology. The performance of these mechanisms is also highlighted in Table 2 and compared to draw a few noteworthy conclusions. Overall, it is noted that these mechanisms are analysed mostly in a low Reynolds number regime, which is well suited in the operating regime of a MAV or a small UAV, and a few tested at high Reynolds number conditions as well. Although topology optimization design approach is a common practice for designing a compliant camber morphing mechanism, concepts that do not employ such tools were found to deflect to just as high angles at the 
trailing edge. Methods and tools to design and analyze the multifunctional behavior of wing morphing-the cause and effects of morphing at different flights conditions-needs to be considered in the two-dimensional design stage, as the ultimate application of the wing is three-dimensional. Researchers need to approach the design problem by integrating specialized knowledge from different fields, similar to the multidisciplinary approach applied in designing a lightweight, cellular structured digital morphing wing [73] and sorts and investigate the operational implications of camber morphing wing technology.

\section{Data Availability}

No data were used to support this study.

\section{Conflicts of Interest}

The authors declare that they have no conflicts of interest.

\section{Acknowledgments}

The authors greatly acknowledge partial funding from the collaboration project with the InnoScience Corporation Inc. (http://www.innosci.co.kr).

\section{References}

[1] I. Dimino, L. Lecce, and R. Pecora, Morphing Wing Technologies: Large Commercial Aircraft and Civil Helicopters, Butterworth-Heinemann, 2017.

[2] T. A. Weisshaar, "Morphing aircraft systems: historical perspectives and future challenges," Journal of Aircraft, vol. 50, no. 2, pp. 337-353, 2013.

[3] S. Kota, J. A. Hetrick, R. Osborn et al., "Design and application of compliant mechanisms for morphing aircraft structures," in Smart Structures and Materials 2003: Industrial and Commercial Applications of Smart Structures Technologies, pp. 24-33, International Society for Optics and Photonics, 2003.

[4] W. Dobrzynski, "Almost 40 years of airframe noise research: what did we achieve?," Journal of Aircraft, vol. 47, no. 2, pp. 353-367, 2010.

[5] R. Pecora, "Morphing wing flaps for large civil aircraft: evolution of a smart technology across the Clean Sky program," Chinese Journal of Aeronautics, vol. 34, no. 7, pp. 13-28, 2021.

[6] S. Kota, R. Osborn, G. Ervin, D. Maric, P. Flick, and D. Paul, "Mission adaptive compliant wing-design, fabrication and flight test," in RTO Applied Vehicle Technology Panel (AVT) Symposium, 2009: RTO-MP-AVT-168, pp. 1-18, Evora, Portugal, 2009.

[7] M. Arena, R. Palumbo, R. Pecora, F. Amoroso, G. Amendola, and I. Dimino, "Flutter clearance investigation of cambermorphing aileron tailored for a regional aircraft," Journal of Aerospace Engineering, vol. 32, no. 2, article 04018146, 2019.

[8] A. Nordmann, "Control surfaces on airfoil.svg," https:// commons.wikimedia.org/wiki/File:Control_surfaces_on_ airfoil.svg.

[9] S. La, W. Y. Joe, M. Akbar, and B. Alsaidi, "Surveys on skin design for morphing wing aircraft: status and challenges," in 2018 AIAA aerospace sciences meeting, p. 0315, Kissimmee, FL, USA, 2018.
[10] D. Li, S. Zhao, A. da Ronch et al., "A review of modelling and analysis of morphing wings," Progress in Aerospace Sciences, vol. 100, pp. 46-62, 2018.

[11] D. Communier, R. M. Botez, and T. Wong, "Design and validation of a new morphing camber system by testing in the price-Païdoussis subsonic wind tunnel," Aerospace, vol. 7, no. 3, p. 23, 2020.

[12] A. Zhao, H. Zou, H. Jin, and D. Wen, "Structural design and verification of an innovative whole adaptive variable camber wing," Aerospace Science and Technology, vol. 89, pp. 11-18, 2019.

[13] Q. Chanzy and A. Keane, "Analysis and experimental validation of morphing UAV wings," The Aeronautical Journal, vol. 122, no. 1249, pp. 390-408, 2018.

[14] S. Meguid, Y. Su, and Y. Wang, "Complete morphing wing design using flexible-rib system," International Journal of Mechanics and Materials in Design, vol. 13, no. 1, pp. 159171, 2017.

[15] T. Yokozeki, A. Sugiura, and Y. Hirano, "Development of variable camber morphing airfoil using corrugated structure," Journal of Aircraft, vol. 51, no. 3, pp. 1023-1029, 2014.

[16] H. Takahashi, T. Yokozeki, and Y. Hirano, "Development of variable camber wing with morphing leading and trailing sections using corrugated structures," Journal of Intelligent Material Systems and Structures, vol. 27, no. 20, pp. 2827-2836, 2016.

[17] M. Maki, "Experimental study of a morphing wing configuration with multi-slotted variable-camber mechanism," in AIAA Atmospheric Flight Mechanics Conference, p. 3849, San Diego, CA, USA, 2016.

[18] Y. Kuya, R. Ito, M. Maki, and K. Sawada, "Numerical study of flowfield around a multislotted high-lift wing," Journal of Aircraft, vol. 58, no. 2, pp. 383-389, 2020.

[19] P. C. Wölcken and M. Papadopoulos, Smart Intelligent Aircraft Structures (SARISTU): Proceedings of the Final Project Conference, Springer, 2015.

[20] R. Pecora, "Multi-modal morphing wing flaps for next generation green regional aircraft: the CleanSky challenge," in Smart Materials, Adaptive Structures and Intelligent Systems, vol. 51944, p. V001T04A018, American Society of Mechanical Engineers, 2018.

[21] R. Pecora, F. Amoroso, R. Palumbo, M. Arena, G. Amendola, and I. Dimino, "Preliminary aeroelastic assessment of a large aeroplane equipped with a camber-morphing aileron," in Industrial and Commercial Applications of Smart Structures Technologies 2017, vol. 10166, p. 101660E, International Society for Optics and Photonics, 2017.

[22] M. Arena, A. Concilio, and R. Pecora, "Aero-servo-elastic design of a morphing wing trailing edge system for enhanced cruise performance," Aerospace Science and Technology, vol. 86, pp. 215-235, 2019.

[23] U. Fasel, D. Keidel, L. Baumann, G. Cavolina, M. Eichenhofer, and P. Ermanni, "Composite additive manufacturing of morphing aerospace structures," Manufacturing Letters, vol. 23, pp. 85-88, 2020.

[24] J. N. Kudva, C. A. Martin, L. B. Scherer et al., "Overview of the DARPA/AFRL/NASA smart wing program," in Smart Structures and Materials 1999: Industrial and Commercial Applications of Smart Structures Technologies, pp. 230-236, International Society for Optics and Photonics, 1999.

[25] J. N. Kudva, "Overview of the DARPA smart wing project," Journal of Intelligent Material Systems and Structures, vol. 15, no. 4, pp. 261-267, 2004. 
[26] Y. Zhang, W. Ge, Z. Zhang, X. Mo, and Y. Zhang, "Design of compliant mechanism-based variable camber morphing wing with nonlinear large deformation," International Journal of Advanced Robotic Systems, vol. 16, no. 6, 2019.

[27] X. Tong, W. Ge, C. Sun, and X. Liu, "Topology optimization of compliant adaptive wing leading edge with composite materials," Chinese Journal of Aeronautics, vol. 27, no. 6, pp. 1488-1494, 2014.

[28] S. Vasista, A. De Gaspari, S. Ricci, J. Riemenschneider, H. P. Monner, and B. van de Kamp, "Compliant structures-based wing and wingtip morphing devices," Aircraft Engineering and Aerospace Technology: An International Journal, 2016.

[29] H. Monner, M. Kintscher, T. Lorkowski, and S. Storm, "Design of a smart droop nose as leading edge high lift system for transportation aircrafts," in 50th AIAA/ASME/ASCE/AHS/ASC Structures, Structural Dynamics, and Materials Conference 17th AIAA/ASME/AHS Adaptive Structures Conference 11th AIAA No, p. 2128, Palm Springs, CA, USA, 2009.

[30] S. Vasista, J. Riemenschneider, B. van de Kamp et al., "Evaluation of a compliant droop-nose morphing wing tip via experimental tests," Journal of Aircraft, vol. 54, no. 2, pp. 519-534, 2017.

[31] A. De Gaspari, L. Riccobene, and S. Ricci, "Design, manufacturing and wind tunnel validation of a morphing compliant wing," Journal of Aircraft, vol. 55, no. 6, pp. 23132326, 2018.

[32] A. De Gaspari and S. Ricci, "A two-level approach for the optimal design of morphing wings based on compliant structures," Journal of Intelligent Material Systems and Structures, vol. 22, no. 10, pp. 1091-1111, 2011.

[33] A. De Gaspari and S. Ricci, "Knowledge-based shape optimization of morphing wing for more efficient aircraft," International Journal of Aerospace Engineering, vol. 2015, Article ID 325724, 19 pages, 2015.

[34] A. De Gaspari and F. Moens, "Aerodynamic shape design and validation of an advanced high-lift device for a regional aircraft with morphing droop nose," International Journal of Aerospace Engineering, vol. 2019, Article ID 7982168, 21 pages, 2019.

[35] A. De Gaspari, V. Cavalieri, and S. Ricci, "Advanced design of a full-scale active morphing droop nose," International Journal of Aerospace Engineering, vol. 2020, Article ID 1086518, 19 pages, 2020.

[36] R. Wu, C. Soutis, S. Zhong, and A. Filippone, "A morphing aerofoil with highly controllable aerodynamic performance," The Aeronautical Journal, vol. 121, no. 1235, pp. 54-72, 2017.

[37] G. Molinari, A. F. Arrieta, and P. Ermanni, “Aero-structural optimization of three-dimensional adaptive wings with embedded smart actuators," AIAA Journal, vol. 52, no. 9, pp. 1940-1951, 2014.

[38] G. Molinari, M. Quack, A. F. Arrieta, M. Morari, and P. Ermanni, "Design, realization and structural testing of a compliant adaptable wing," Smart Materials and Structures, vol. 24, no. 10, article 105027, 2015.

[39] G. Molinari, A. F. Arrieta, M. Guillaume, and P. Ermanni, "Aerostructural performance of distributed compliance morphing wings: wind tunnel and flight testing," AIAA Journal, vol. 54, no. 12, pp. 3859-3871, 2016.

[40] D. Keidel, G. Molinari, and P. Ermanni, “Aero-structural optimization and analysis of a camber-morphing flying wing: structural and wind tunnel testing," Journal of Intelligent
Material Systems and Structures, vol. 30, no. 6, pp. 908-923, 2019.

[41] B. K. S. Woods and M. I. Friswell, "Preliminary investigation of a fishbone active camber concept," in Smart Materials, Adaptive Structures and Intelligent Systems, pp. 555-563, American Society of Mechanical Engineers, 2012.

[42] B. K. Woods, O. Bilgen, and M. I. Friswell, "Wind tunnel testing of the fish bone active camber morphing concept," Journal of Intelligent Material Systems and Structures, vol. 25, no. 7, pp. 772-785, 2014.

[43] B. K. Woods and M. I. Friswell, "Structural characterization of the fish bone active camber morphing airfoil," in 22nd AIAA/ ASME/AHS adaptive structures conference, p. 1122, National Harbor, MD, USA, 2014.

[44] A. E. Rivero, P. M. Weaver, J. E. Cooper, and B. K. Woods, "Parametric structural modelling of fish bone active camber morphing aerofoils," Journal of Intelligent Material Systems and Structures, vol. 29, no. 9, pp. 2008-2026, 2018.

[45] A. E. Rivero, P. M. Weaver, J. E. Cooper, and B. K. Woods, "Structural modeling of compliance-based camber morphing structures under transverse shear loading," AIAA Journal, vol. 58, no. 11, pp. 4941-4951, 2020.

[46] R. Botez, "Morphing wing, UAV and aircraft multidisciplinary studies at the Laboratory of Applied Research in Active Controls, Avionics and AeroServoElasticity LARCASE," Aerospace Lab, vol. 14, pp. 1-11, 2018.

[47] A. V. Popov, T. L. Grigorie, R. M. Botez, Y. Mébarki, and M. Mamou, "Modeling and testing of a morphing wing in open-loop architecture," Journal of Aircraft, vol. 47, no. 3, pp. 917-923, 2010.

[48] A. Koreanschi, O. Sugar-Gabor, and R. M. Botez, "Numerical and experimental validation of a morphed wing geometry using Price-Païdoussis wind-tunnel testing," The Aeronautical Journal, vol. 120, no. 1227, pp. 757-795, 2016.

[49] A. Koreanschi, M. B. Henia, O. Guillemette et al., "Flutter analysis of a morphing wing technology demonstrator: numerical simulation and wind tunnel testing," INCAS Bulletin, vol. 8, no. 1, pp. 99-124, 2016.

[50] K. Zhao, J. P. Schmiedeler, and A. P. Murray, "Design of planar, shape-changing rigid-body mechanisms for morphing aircraft wings," Journal of Mechanisms and Robotics, vol. 4, no. $4,2012$.

[51] B. Li and G. Li, "Analysis and optimization of a camber morphing wing model," International Journal of Advanced Robotic Systems, vol. 13, no. 5, 2016.

[52] G. Li, Z. Miao, B. Li, and Y. Hu, "Type synthesis to design variable camber mechanisms," Advances in Mechanical Engineering, vol. 8, no. 8, 2016.

[53] H. L. Şahin and Y. Yaman, "Synthesis, analysis, and design of a novel mechanism for the trailing edge of a morphing wing," Aerospace, vol. 5, no. 4, p. 127, 2018.

[54] A. V. Ivchenko, N. Sharonov, and R. Ziatdinov, "New conceptual design of the adaptive compliant aircraft wing frame," Engineering Science and Technology, an International Journal, vol. 22, no. 5, pp. 1149-1154, 2019.

[55] K. Maute and G. W. Reich, "Integrated multidisciplinary topology optimization approach to adaptive wing design," Journal of Aircraft, vol. 43, no. 1, pp. 253-263, 2006.

[56] A. P. Milojević and N. D. Pavlović, "Development of a new adaptive shape morphing compliant structure with embedded 
actuators," Journal of Intelligent Material Systems and Structures, vol. 27, no. 10, pp. 1306-1328, 2016.

[57] M. Santer and S. Pellegrino, "Topological optimization of compliant adaptive wing structure," AIAA Journal, vol. 47, no. 3, pp. 523-534, 2009.

[58] L. Shili, G. Wenjie, and L. Shujun, "Optimal design of compliant trailing edge for shape changing," Chinese Journal of Aeronautics, vol. 21, no. 2, pp. 187-192, 2008.

[59] I. K. Kuder, U. Fasel, P. Ermanni, and A. F. Arrieta, "Concurrent design of a morphing aerofoil with variable stiffness bistable laminates," Smart Materials and Structures, vol. 25, no. 11, article 115001, 2016.

[60] A. Bhattacharyya, C. Conlan-Smith, and K. A. James, "Design of a bi-stable airfoil with tailored snap-through response using topology optimization," Computer-Aided Design, vol. 108, pp. 42-55, 2019.

[61] J. Xie, J. B. McGovern, R. Patel, W. Kim, S. Dutt, and A. D. Mazzeo, "Elastomeric actuators on airfoils for aerodynamic control of lift and drag," Advanced Engineering Materials, vol. 17, no. 7, pp. 951-960, 2015.

[62] H. Li, L. Liu, T. Xiao, and H. Ang, "Design and simulative experiment of an innovative trailing edge morphing mechanism driven by artificial muscles embedded in skin," Smart Materials and Structures, vol. 25, no. 9, article 095004, 2016.

[63] P. Zhang, L. Zhou, W. Cheng, and T. Qiu, "Conceptual design and experimental demonstration of a distributedly actuated morphing wing," Journal of Aircraft, vol. 52, no. 2, pp. 452461, 2015.

[64] R. Vos and R. Barrett, "Mechanics of pressure-adaptive honeycomb and its application to wing morphing," Smart Materials and Structures, vol. 20, no. 9, article 094010, 2011.

[65] S. Vasista and L. Tong, "Topology-optimized design and testing of a pressure-driven morphing-aerofoil trailing-edge structure," AIAA Journal, vol. 51, no. 8, pp. 1898-1907, 2013.

[66] H. Heo, J. Ju, and D.-M. Kim, "Compliant cellular structures: application to a passive morphing airfoil," Composite Structures, vol. 106, pp. 560-569, 2013.

[67] K. Taguchi, K. Fukunishi, S. Takazawa et al., "Experimental study about the deformation and aerodynamic characteristics of the passive morphing airfoil," Transactions of the Japan Society for Aeronautical and Space Sciences, vol. 63, no. 1, pp. 18-23, 2020.

[68] V. H. Alulema, E. A. Valencia, D. Pillajo, M. Jacome, J. Lopez, and B. Ayala, "Degree of deformation and power consumption of compliant and rigid-linked mechanisms for variablecamber morphing wing UAVs," in AIAA Propulsion and Energy 2020 Forum, p. 3958, Virtual Event, 2020.

[69] S. Barbarino, O. Bilgen, R. M. Ajaj, M. I. Friswell, and D. J. Inman, "A review of morphing aircraft," Journal of Intelligent Material Systems and Structures, vol. 22, no. 9, pp. 823-877, 2011.

[70] J. Sun, Q. Guan, Y. Liu, and J. Leng, "Morphing aircraft based on smart materials and structures: a state-of-the-art review," Journal of Intelligent Material Systems and Structures, vol. 27, no. 17, pp. 2289-2312, 2016.

[71] Z. Zhang, C. Song, C. Yang, V. Cavalieri, A. De Gaspari, and S. Ricci, "Combining density-based approach and optimization refinement in the design of morphing airfoil structures," in AIAA Scitech 2020 Forum, p. 1546, Virtual Event, 2020.
[72] A. Suleman, J. L. Vale, F. Afonso et al., "Novel air vehicle configurations: from fluttering wings to morphing flight," in World Congress on Computational Mechanics (WCCM XI), pp. 20-25, Barcelona, Spain, 2014.

[73] B. Jenett, S. Calisch, D. Cellucci et al., "Digital morphing wing: active wing shaping concept using composite lattice-based cellular structures," Soft Robotics, vol. 4, no. 1, pp. 33-48, 2017. 